\title{
Glycemic Control Rate in Type 2 Diabetes Mellitus Patients at a Public Referral Hospital in Rio de Janeiro, Brazil: Demographic and Clinical Factors
}

\author{
Natasha Reis Lozovey ${ }^{\mathrm{a}}$, Elisa Baranski Lamback ${ }^{\mathrm{a}}$, Raissa Barros Mota ${ }^{\mathrm{a}}$, \\ Michelle Botelho Caarls ${ }^{\mathrm{b}, \mathrm{c}}$, Leonardo Vieira Neto ${ }^{\mathrm{a}, \mathrm{d}, \mathrm{e}}$
}

\begin{abstract}
Background: The aim of the study was to determine the rate of satisfactory glycemic control among patients with type 2 diabetes (T2D) followed up at a tertiary referral hospital in Brazil.

Methods: A retrospective and observational study was conducted between September 2014 and September 2015, by collecting data from medical records.

Results: Data were obtained from 1,001 patients. The majority of patients were women (68\%), with a median age of 61 years old $(21-95)$. The median duration of disease was 10 years $(1-58)$. Satisfactory glycemic control rate was found in $51 \%$ of patients. The strongest factors related to good control were: younger age $(\mathrm{P}<0.001)$; absence of a T2D family history $(\mathrm{P}=0.04)$, obesity $(\mathrm{P}<0.001)$, overweight $(\mathrm{P}<0.001)$, and absence of current alcohol consumption $(\mathrm{P}=0.006)$; presence of fewer comorbidities $(\mathrm{P}=0.01)$, chronic kidney disease $(\mathrm{P}$ $=0.004)$, and the treatment using only oral antidiabetic drugs (OADs) $(\mathrm{P}<0.001)$.
\end{abstract}

Conclusions: The majority of patients obtained an adequate glycemic control rate, particularly among those using only OAD. Younger age, a negative family history of T2D, normal body mass index, absence of current alcohol consumption, presence of fewer comorbidities, and chronic kidney disease were associated with better glycemic control.

Keywords: Type 2 diabetes; Glycemic control; Glycated hemo-

Manuscript accepted for publication February 22, 2017

aEndocrinology Section, Hospital Federal da Lagoa, Rua Jardim Botanico, 501, Bairro Lagoa, Rio de Janeiro, Brazil

b Institute of Biomedical Sciences, Universidade Federal do Rio de Janeiro, Rio de Janeiro, Brazil

'Laboratorio de Inflamacao, Institute of Biophysics Carlos Chagas Filho, Universidade Federal do Rio de Janeiro, Rio de Janeiro, Brazil

${ }^{\mathrm{d}}$ Department of Internal Medicine and Endocrinology Section, Medical School and Hospital Universitario Clementino Fraga Filho, Universidade Federal do Rio de Janeiro, Rio de Janeiro, Brazil

${ }^{e}$ Corresponding Author: Leonardo Vieira Neto, Rua Professor Rodolpho Paulo Rocco, 255, Ninth Floor, Endocrine Section, Ilha do Fundao, Rio de Janeiro/ RJ, Brazil. Email: netolv@gmail.com

doi: https://doi.org/10.14740/jem390w globin; Brazil

\section{Introduction}

As stated by the International Diabetes Federation (IDF), 415 million individuals worldwide have diabetes mellitus, which is equivalent to $8.8 \%$ of the population. Brazil is the fourth largest country harboring diabetic patients, behind China, India and the United States, and the fifth regarding the highest costs. Brazil's adult population, aged between 20 and 79 years, accounts for approximately 134 million individuals, with a current prevalence of $10.2 \%$ of diabetes, and an estimated incidence of 23.3 million people in 2040 [1]. Type 2 diabetes (T2D) is considered an epidemic in both developed and in developing countries, and represents a social and economic burden, with a cost estimated in 2015 of 673 billion US dollars [1]. Microvascular and macrovascular complications are common, making diabetes mellitus an extremely onerous disease, leading to diminished life quality and productivity $[2,3]$.

Data from several epidemiological studies worldwide have shown that the majority of patients do not obtain, nor maintain glycemic control among satisfactory range defined by international societies [4-8]. Thus, diabetes' management remains challenging.

This study aimed to assess glycemic control rate and the demographic and clinical factors associated with glycemic control in patients with T2D in a public Brazilian referral hospital.

\section{Materials and Methods}

An observational, retrospective study was conducted between September 2014 and September 2015, at the Endocrinology Section of the Hospital Federal da Lagoa (HFL). All patients were seen by an endocrinologist in this tertiary referral center. Inclusion criteria were predefined as follows: patients with age more than 18 years old, diagnosed with T2D, with a regular follow-up and at least one available glycated hemoglobin (HbA1c) assessment during the studied period. Exclusion criteria included the following: 1) other types of diabetes (such as type 1 diabetes, latent autoimmune diabetes in adults, maturi- 
ty-onset of diabetes of the young, and gestational diabetes); 2) an uncertain diagnosis; 3 ) an irregular follow-up with no medical visits in the studied period; 4) patients with unavailable HbA1c measurement. First-visit patients were not included in this because they were not formerly followed up at our Endocrinology Department.

The following data were collected from medical records: gender, age at the last consultation, diabetes duration (in years), first degree family history of T2D, smoking, alcohol consumption, comorbidities (hypertension, dyslipidemia, overweight or obesity, chronic kidney disease (CKD)), nutritional therapy, type of treatment, body mass index $\left(\mathrm{BMI} ; \mathrm{kg} / \mathrm{m}^{2}\right)$, waist circumference (WC; $\mathrm{cm})$ and HbA1c (\%).

According to the American Diabetes Association (ADA), a diagnosis of diabetes can be established in the presence of any of the following (two tests are required): 1) fasting plasma glucose levels of $\geq 126 \mathrm{mg} / \mathrm{dL} ; 2$ ) random plasma glucose $\geq$ $200 \mathrm{mg} / \mathrm{dL}$ in a patient with classic symptoms of hyperglycemia; 3) 2-h plasma glucose level $\geq 200 \mathrm{mg} / \mathrm{dL}$ during a $75 \mathrm{~g}$ oral glucose tolerance test; 4) HbA1c level of $\geq 6.5 \%$ [9].

Smoking was characterized by current smoking, associated to mental and behavioral disorder due to nicotine dependence syndrome. Patients were screened as positive if they reported any smoking practice in the past year. Alcohol consumption was considered positive if abusive, with behavioral and cognitive consequences, according to the 10th edition of the International Classification of Diseases and the World Health Organization [10]. Ex-smokers or ex-alcoholics were considered as former smokers or alcoholics if none of these habits were reported in the last medical visit. Regarding comorbidities, hypertension was defined as a systolic blood pressure $\geq 140 \mathrm{~mm}$ $\mathrm{Hg}$ and/or diastolic blood pressure $\geq 90 \mathrm{~mm} \mathrm{Hg}$ in at least two measurements during consultation, or in patients already taking antihypertensive medication [11]; dyslipidemia was present if one or more of the following were observed: 1) low-density lipoprotein-cholesterol (LDL-c) $\geq 160 \mathrm{mg} / \mathrm{dL}$, triglycerides $\geq 150 \mathrm{mg} / \mathrm{dL}$, total cholesterol $\geq 400 \mathrm{mg} / \mathrm{dL}$ when triglyceride $\geq 400 \mathrm{mg} / \mathrm{dL}$ (due to inadequate LDL-c calculation with Friedewald's formula) or high-density lipoprotein-cholesterol (HDL-c) $<40 \mathrm{mg} / \mathrm{dL}$ in men and $<50 \mathrm{mg} / \mathrm{dL}$ for women [12]; CKD was considered positive if progressive, irreversible loss of kidney function with normal glomerular filtration rate (GFR; $\left.\geq 90 \mathrm{~mL} / \mathrm{min} / 1.73 \mathrm{~m}^{2}\right)$ was present, or abnormal GFR $(\leq 89$ $\mathrm{mL} / \mathrm{min} / 1.73 \mathrm{~m}^{2}$ ), or in patients already being followed up by a nephrologist, or those with a pre-established albuminuria [13].

Additionally, patients were divided into two treatment groups: those without medication (only lifestyle changes, such as low carbohydrate diets and regular physical exercise); and those taking medications: only oral antidiabetic drug (OAD); OAD + insulin; only basal insulin; or basal + bolus insulin.

A wide range of antidiabetic medications were prescribed, such as biguanides (metformin), sulfonylureas, thiazolidinediones, meglitinide derivatives, alpha-glucosidase inhibitors, glucagon-like peptide-1 (GLP-1) agonists, dipeptidyl peptidase IV (DPP-4) inhibitors and selective sodium-glucose transporter-2 (SGLT-2) inhibitors. With respect to insulin therapy, intermediate insulin (NPH), rapid insulin (regular), long-acting insulin analogues (detemir, glargine or degludec) and ultra-rapid analogues (glulisine, lispro or aspart) were prescribed.
Table 1. Clinical and Demographic Data

\begin{tabular}{|c|c|}
\hline Variables & Total, n (\%) \\
\hline Male/female & $321(32.0 \%) / 680(68.0 \%)$ \\
\hline Age $^{\mathrm{a}}$ (years) & $61(21-95)$ \\
\hline Diabetes duration (years) & $10(1-58)$ \\
\hline T2D family history $(\mathrm{n}=527)$ & $352(66.8 \%)$ \\
\hline \multicolumn{2}{|l|}{ Smoking $(n=639)$} \\
\hline Passed $/$ present & $236(37.0 \%) / 69(10.8 \%)$ \\
\hline \multicolumn{2}{|l|}{ Alcohol consumption $(n=589)$} \\
\hline Previous $\mathrm{b} /$ Present & $48(8.1 \%) / 11(1.8 \%)$ \\
\hline Hypertension & $812(81.1 \%)$ \\
\hline Dyslipidemia & $751(75.0 \%)$ \\
\hline CKD & $185(18.5 \%)$ \\
\hline \multicolumn{2}{|l|}{ Treatment } \\
\hline Only OAD & $460(46.0 \%)$ \\
\hline OAD + insulin & $363(36.3 \%)$ \\
\hline Only basal insulin & $54(5.4 \%)$ \\
\hline Basal + bolus insulin & $102(10.2 \%)$ \\
\hline Nutritional follow-up $(\mathrm{n}=898)$ & $331(36.9 \%)$ \\
\hline Waist circumference $(\mathrm{cm})(\mathrm{n}=206)$ & $100(72-150)$ \\
\hline $\mathrm{BMI}\left(\mathrm{kg} / \mathrm{m}^{2}\right)$ & $29.50(16.17-57.00)$ \\
\hline Overweight/obesity & $223(22.3 \%) / 302(30.2 \%)$ \\
\hline HbA1c (\%) & $7.3(4.3-15.2)$ \\
\hline
\end{tabular}

${ }^{a}$ Age, patient's age obtained at last evaluation. ${ }^{b}$ Former practice no longer present in the last medical visit. T2D: type 2 diabetes; CKD: chronic kidney disease; OAD: oral antidiabetic medication; BMI: body mass index; HbA1c: glycated hemoglobin.

BMI was determined by dividing the weight in $\mathrm{kg}$ by the square of the height in meters and classified as normal (18.5 $\left.24.9 \mathrm{~kg} / \mathrm{m}^{2}\right)$, overweight $\left(25.0-29.9 \mathrm{~kg} / \mathrm{m}^{2}\right)$ or obese $(\geq 30.0$ $\mathrm{kg} / \mathrm{m}^{2}$ ) [14]. WC was measured at midpoint between the inferior limit of the lowest rib and the superior limit of the iliac crest, with the measure tape placed horizontally [15], and considered abnormal if: $\geq 90 \mathrm{~cm}$ in men and $\geq 80 \mathrm{~cm}$ in women.

$\mathrm{HbA1c}$ was determined by high performance liquid chromatography, a certified method by the Glycohemoglobin Standartization Program, in the equipment Premier Hb9210 ${ }^{\mathrm{TM}}$, with the software Affinity ${ }^{\mathrm{TM}}$, with an acceptable error range of 0.067 . Adequate or satisfactory glycemic control target was defined according to the latest recommendations from ADA and from the Brazilian Diabetes Society (SBD) as a HbA1c lower than $7.0 \%$ for adults and below $8.0 \%$ for patients aged more than 70 years old, with serious microvascular or macrovascular complications, presence of severe hypoglycemia or several comorbidities, or with a limited life expectancy [9-17].

The statistical analyses were performed using SPSS version 20.0 for MacOS (SPSS Inc., Chicago, IL). None of the variables were found to follow a normal distribution using the Kolmogorov-Smirnov test. For the descriptive analysis, categorical variables were expressed as the percentage and frequency, and 
Table 2. Factors Related to Satisfactory Glycemic Control Rate

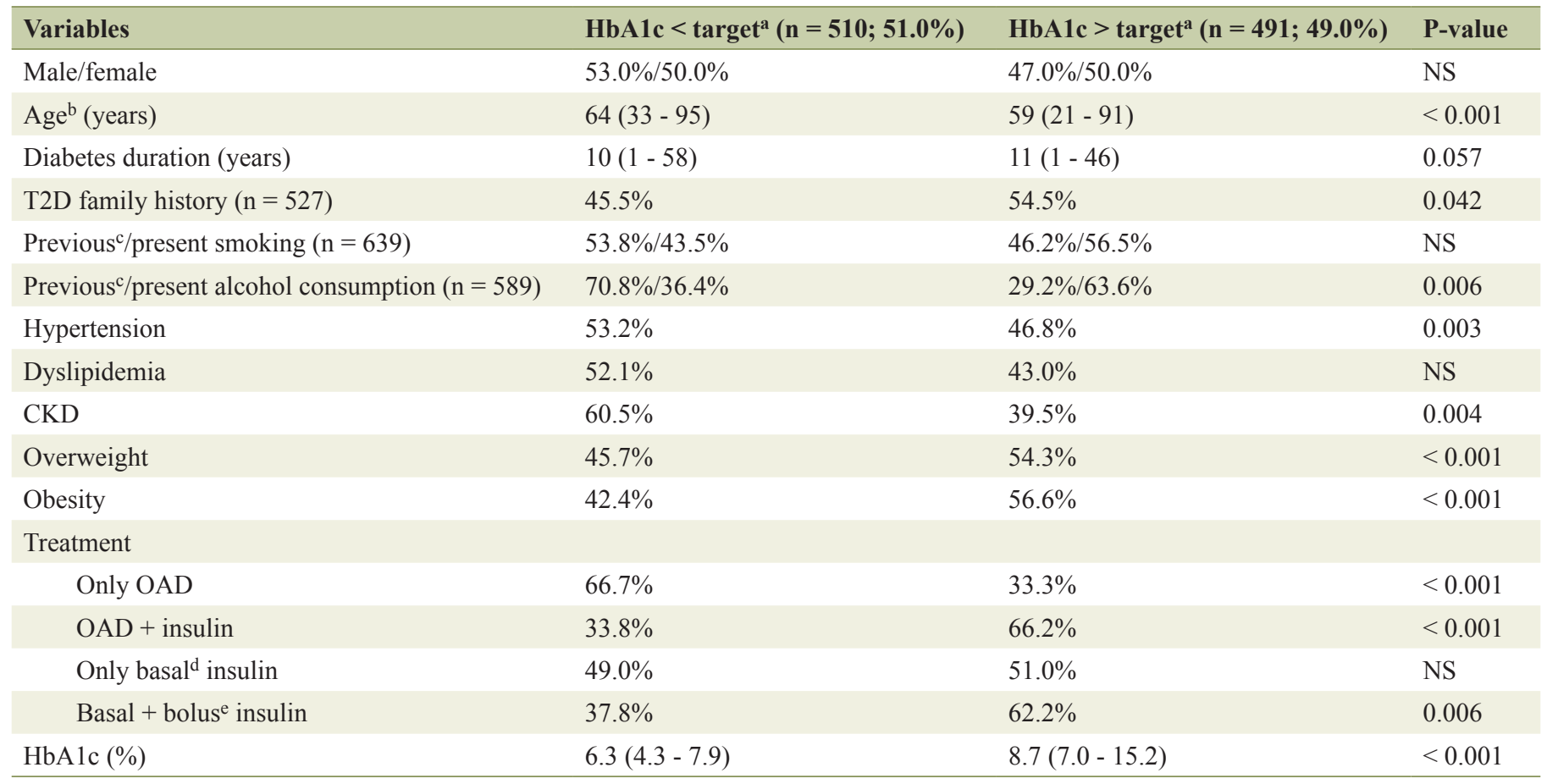

aFor this analysis, we considered ADA's goals for T2D patients as: $\mathrm{HbA} 1 \mathrm{c}<7.0 \%$ for young adults and $<8.0 \%$ for older than 70 years old, with serious microvascular or macrovascular complications, presence of severe hypoglycemia or several comorbidities, or with a limited life expectancy. ${ }^{\mathrm{b}} \mathrm{Age}$

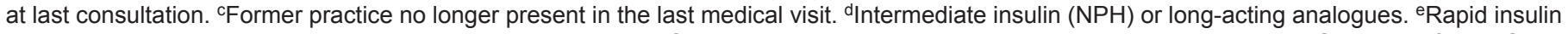
(regular) or ultra-rapid acting analogues. T2D: type 2 diabetes; CKD: chronic kidney disease; HbA1c: glycated hemoglobin; NS: not significant; OAD: oral antidiabetic medication.

numerical variables were expressed as median (minimum maximum). The Mann-Whitney U test was performed to compare the numerical variables between the two groups. Fisher's exact test and Chi-square test were used to compare categorical variables. A P-value $<0.05$ was considered statistically significant and $\mathrm{P}$-values $\geq 0.05$ and $\leq 0.09$ were considered to indicate a tendency towards statistical significance.

\section{Results}

Clinical and epidemiological data of the 1,001 patients included in this study are shown in Table 1.

The majority of patients were women $(68.0 \%)$, with a median age of 61 years old (21 - 95). The median time of disease was 10 years $(1-58)$, with T2D family history found in $66.8 \%$ of cases. Regarding lifestyle habits, the majority did not abuse of alcohol or smoke. The median BMI and WC were $29.5 \mathrm{~kg} /$ $\mathrm{m}^{2}$ (16.2 - 57.0) and $100 \mathrm{~cm}$ (72 - 150), respectively. Regarding comorbidities, $74 \%$ of patients had two or three comorbidities. Analyzed separately, $81.1 \%$ had hypertension, $75.0 \%$ had dyslipidemia, $52.5 \%$ were overweight or obese, and $18.5 \%$ had CKD (Table 1).

Medications were prescribed in approximately $98 \%$ of patients, of which $46 \%$ used only OAD, almost $37 \%$ used OAD + insulin, 10\% used only insulin (including basal and bolus injections) and 5.4\% used only basal insulin. Almost 37\% had regular follow-up with dieticians (Table 1).

The majority of patients $(51.0 \%)$ had satisfactory glycemic control, with a median HbA1c of 7.3\% (4.3-15.2\%). Demographic and clinical factors associated with satisfactory glycemic control included older age at last consultation $(\mathrm{P}<$ $0.001)$, presence of hypertension $(\mathrm{P}=0.003)$, and chronic kidney disease $(\mathrm{P}=0.004)$. A shorter duration of diabetes tended to correlate with better glycemic control $(\mathrm{P}=0.057)$.

Inadequate glycemic control was found in the presence of a positive family history of T2D $(\mathrm{P}=0.04)$, current alcohol consumption $(0.006)$, presence of overweight $(\mathrm{P}<0.001)$ or obesity $(\mathrm{P}<0.001)$. Additionally, the combination of three or four comorbidities was associated with an increased $\mathrm{HbAlc}$, above satisfactory range in the majority of cases $(\mathrm{P}=0.01)$. No statistical significance was found in relation to gender, smoking and dyslipidemia (Table 2).

Regarding medical treatment in the controlled group, almost $67.0 \%$ only used OAD and, in the uncontrolled group, $66.2 \%$ of patients used OAD + insulin and $62.2 \%$ used basal + bolus insulin. There was no statistical significance between $\mathrm{HbA} 1 \mathrm{c}$ and the use of basal insulin only, or HbA1c and patients who took no medication (Table 2).

\section{Discussion}

This study evaluated the treatment of 1,001 T2D patients fol- 
lowed up at a tertiary referral hospital in Brazil. Data analysis brought interesting and valuable information from a substantial number of patients. Only a few studies in Brazil analyzing glycemic control rate and its association with demographic and clinical characteristics are available. In this series, satisfactory glycemic control was present in the majority of patients, a finding not consistently observed in other studies in Brazil.

Compared to our study, other Brazilian studies by Malerbi and Franco [18] and Borges et al [19] showed similar results to our epidemiological profile: higher prevalence of diabetes in patients aged 60 - 69 years old, in female patients and with a positive family history of T2D. Malerbi and Franco found a two-fold increase in the prevalence of diabetes if a family history was present [18]. Regarding gender, the IDF mentions that T2D is more common in men worldwide, but in South and Central America the prevalence is higher in women [1]. Among comorbidities, the association between T2D and hypertension is well known, as are the abuse of alcohol and dyslipidemia, as well as BMI and WC above normal range, regardless of gender or age $[18,20-23]$. Obesity, especially central obesity, is a key factor in the pathophysiology of insulin resistance and diabetes [24]. A wider WC alone leads to increased risk of metabolic syndrome and cardiovascular disease [1].

The objective of this study was to analyze the satisfactory glycemic control rate of patients treated in HFL, based on the latest recommendations of international and national societies - Brazilian Diabetes Society (SBD), ADA and American Association of Clinical Endocrinologists [17, 25, 26].

The majority of patients had adequate glycemic control (51\%), with a median HbAlc of $6.3 \%$ (4.3-7.9\%), showing more excellent glycemic control as compared with Tunisia (16.7\%) [4], United Kingdom (24\%) [5], Canada (27\%) [27], Lithuania (34.5\%) [28] and Denmark (49\%) [29]. A meta-analysis of 137 randomized controlled trials, conducted in 2011, with a total of 39,845 patients, found a satisfactory control rate of $25.9-48.6 \%$, considered a wide range depending on the OAD taken [30]. Another study conducted in 2008 with 2,023 patients in seven European countries revealed a glycemic control rate of 20-29.6\% of cases only [31]. Lopez et al, in a multicenter Latin American study, found a satisfactory glycemic control rate in $43.2 \%$ of patients [7].

With respect to Brazilian studies, much lower control rates are seen compared to those found in our study: $26 \%$ in a study conducted between 2006 and 2007 by Borges et al [19] and $40 \%$ in a multicenter study in 2007 with 878 patients [7]. Another Brazilian study performed between 2006 and 2011, with 5,750 diabetic patients seen in a public health system found mean $\mathrm{HbAlc}$ of $8.1 \%(8.6 \pm 2.2 \%)$ [6]. However, in our study, $49 \%$ of our patients were above glycemic control target, with a median $\mathrm{HbA} 1 \mathrm{c}$ of $8.7 \%$, a worse percentage than encountered in, for example, Germany (40\%) [32], the Netherlands (42\%) [33] and USA (43\%) [34].

Analyzing glycemic control rate factors, Borges et al also found a worse control as diabetes' duration progressed [19]. The presence of alcohol abuse was a poor control factor, as well as overweight and obesity and the presence of multiple comorbidities. T2D and hypertension alone increase cardiovascular and CKD risks [20]. Visceral adiposity has been researched more intensively in recent years, with several stud- ies showing its relationship as a determinant of hypertension, insulin resistance and dyslipidemia, all defining comorbidities of the metabolic syndrome, with a significant increase in morbidity and mortality from cardiovascular disease $[35,36]$. In Switzerland, in a study conducted in $2002,42.5 \%$ of T2D's cases were attributed to obesity [37].

The presence of systemic arterial hypertension, when analyzed separately in our study, was a factor of good glycemic control rate, possibly because these patients have more frequent medical visits and, apart from endocrinologists, they are followed up by general practitioner or cardiologist, and take more seriously lifestyle changes and have better adherence to drug treatment. Similarly, a satisfactory control rate was found in CKD patients ( $60.5 \%$ vs. $39.5 \%)$, which could be explained by decreased progressive renal gluconeogenesis, worse insulin clearance and increased insulin sensitivity in CKD patients, which may even lead to severe and frequent hypoglycemia $[38,39]$. Another possible explanation is the shorter half-life of red blood cells (RBC), leading to lower HbAlc level, either by hemolysis in patients on hemodialysis, or by anemia due to deficiency in the production of erythropoietin, or by folic acid deficiency. Any of these reasons can interfere with HbAlc's measurement, leading to erroneous low values. Furthermore, the increase in turnover of $\mathrm{RBC}$ due to the use of recombinant erythropoietin may be also associated with lower HbAlc levels in patients with CKD [40, 41].

Regarding treatment, an adequate glycemic control rate was observed in most patients using OAD alone. In contrast, only one-third of patients using insulin + OAD had satisfactory glycemic control rate, regardless of the type of insulin, and only $37.8 \%$ had $\mathrm{HbA} 1 \mathrm{c}$ below target with the use of basal + bolus insulin. Therefore, these combinations show a worsening in T2D's control, as reported in another Brazilian study conducted in 2007 by Borges et al [19] and a Greek study in 2012 [42]. Some plausible explanations could be that possibly the patients using insulin have worse T2D, with more difficulties found in achieving good glycemic control and using several combinations of antidiabetic and insisting on it could have postponed a proper T2D control. Maybe these patients should have been intensively treated with insulin earlier. Patients with mild T2D can be treated by only OADs; however, patients with severe T2D whose pancreatic beta cells were severely disturbed cannot be treated by only $\mathrm{OAD}$, and need the insulin therapy. Other studies proclaim that introducing basal insulin or basal + bolus led to significant weight gain, perhaps leading to worse glucose control [43]. Also, Borges et al mentioned that treatment with oral medications may be simpler and easier, therefore being more efficient in T2D's control [19]. Clearly, more studies are needed regarding T2D's treatment to elucidate these uncertainties.

Treatment regimens that reduce $\mathrm{HbA} 1 \mathrm{c}$ target below 7\% and $8 \%$ (in pre-defined cases) have been associated with lower incidence of macrovascular and microvascular complications over time. In the era of intensive glycemic control, the Diabetes Control and Complications Trial (DCCT) showed that effective glucose control contributes to a decrease in the risk of microvascular complications in T1D [16]. The United Kingdom Prospective Diabetes Study (UKPDS) initially showed no statistical significance in reducing vascular events with inten- 
sive glycemic control in T2D, but after 10 years of follow-up, evidence showed that for every $1 \%$ reduction in mean $\mathrm{HbAlc}$, there was a decrease of $37 \%$ in microvascular complications, $14 \%$ in fatal and non-fatal myocardial infarction and $43 \%$ in amputation rate or death from peripheral vascular disease. This protective factor underlying metabolic memory still remained effective after the study was concluded [44].

Our study had some limitations. Since it was carried out in a single care center, data may not be transferable to all endocrine centers in the country. The regional distribution of patients, access to health care centers and the severity of the disease in each population could also be different, apart from the divergence in methods of data collection, the measurement of $\mathrm{HbAlc}$ and the definition of the T2D control target.

In conclusion, achieving adequate control in T2D is difficult but manageable. In this study, the majority of T2D patients obtained satisfactory glycemic control. The treatment using only OADs was more effective in reaching target $\mathrm{HbA} 1 \mathrm{c}$ compared to insulin alone or associated with OAD, perhaps because of a milder T2D. Other important positive factors of good metabolic control were younger age at the last consultation, the absence of a positive family history of T2D, absence of current alcohol consumption, normal BMI, the presence of fewer comorbidities, and the presence of CKD.

\section{Acknowledgments}

We would like to thank the Endocrinology Service at HFL (Amanda Torres, Andrea Ferreira, Andreia Buzza, Carmine Osso, Daniel Bulzico, Deborah Livi, Eline Romagna, Fabiana Melnik, Fernanda Junqueira, Helena Bandeira, Julia Souza, Lara Moreira, Roberto Zagury, Ronaldo Sinay, Samira Oliveira, Silvio Voscaboinik, and Yasmine Ddine).

\section{Conflicts of Interest}

The authors have nothing to declare.

\section{Author Contributions}

Study design: Leonardo Vieira Neto. Study conduct: Leonardo Vieira Neto and Natasha Reis Lozovey. Literature review: Leonardo Vieira Neto, Natasha Reis Lozovey, Elisa Baranski Lamback, Raissa Barros Mota and Michelle Botelho Caarls. Data collection: Natasha Reis Lozovey and Raissa Barros Mota. Data analysis: Leonardo Vieira Neto, Natasha Reis Lozovey and Raissa Barros Mota. Data interpretation: Leonardo Vieira Neto, Natasha Reis Lozovey, Elisa Baranski Lamback, Raissa Barros Mota and Michelle Botelho Caarls. Drafting manuscript: Natasha Reis Lozovey and Elisa Baranski Lamback. Revising manuscript content: Leonardo Vieira Neto and Michelle Botelho Caarls. Approving final version of manuscript: Leonardo Vieira Neto, Natasha Reis Lozovey, Elisa Baranski Lamback, Raissa Barros Mota and Michelle Botelho Caarls. Leonardo Vieira Neto takes responsibility for the integ- rity of the data analysis.

\section{Abbreviations}

ADA: American Diabetes Association; BMI: body mass index; CKD: chronic kidney disease; DCCT: Diabetes Control and Complications Trial; F: female; HbAlc: glycated hemoglobin; HDL-c: high-density lipoprotein-cholesterol; HFL: Hospital Federal da Lagoa; IDF: International Diabetes Federation; LADA: latent autoimmune diabetes in adults; LDL-c: lowdensity lipoprotein-cholesterol; M: male; MODY: maturityonset of diabetes of the young; NGSP: National Glycohemoglobin Standardization Program; NPH: intermediate insulin; RBC: red blood cells; SBD: Brazilian Diabetes Society; T2D: type 2 diabetes; UKPDS: United Kingdom Prospective Diabetes Study; WC: waist circumference; WHO: World Health Organization

\section{References}

1. Federation ID. IDF Diabetes Atlas. In. 7 ed; 2015.

2. Organization WH. Diabetes: the cost of diabetes. WHO fact sheet. In; 2002.

3. Valdmanis V, Smith DW, Page MR. Productivity and economic burden associated with diabetes. Am J Public Health. 2001;91(1):129-130.

4. Ben Abdelaziz A, Soltane I, Gaha K, Thabet H, Tlili H, Ghannem H. [Predictive factors of glycemic control in patients with type 2 diabetes mellitus in primary health care]. Rev Epidemiol Sante Publique. 2006;54(5):443452.

5. Fox KM, Gerber Pharmd RA, Bolinder B, Chen J, Kumar S. Prevalence of inadequate glycemic control among patients with type 2 diabetes in the United Kingdom general practice research database: A series of retrospective analyses of data from 1998 through 2002. Clin Ther. 2006;28(3):388-395.

6. Viana LV, Leitao CB, Kramer CK, Zucatti AT, Jezini DL, Felicio J, Valverde AB, et al. Poor glycaemic control in Brazilian patients with type 2 diabetes attending the public healthcare system: a cross-sectional study. BMJ Open. 2013;3(9):e003336.

7. Lopez Stewart G, Tambascia M, Rosas Guzman J, Etchegoyen F, Ortega Carrion J, Artemenko S. Control of type 2 diabetes mellitus among general practitioners in private practice in nine countries of Latin America. Rev Panam Salud Publica. 2007;22(1):12-20.

8. Koro CE, Bowlin SJ, Bourgeois N, Fedder DO. Glycemic control from 1988 to 2000 among U.S. adults diagnosed with type 2 diabetes: a preliminary report. Diabetes Care. 2004;27(1):17-20.

9. (2) Classification and diagnosis of diabetes. Diabetes Care. 2015;38(Suppl):S8-S16.

10. Organization WH. In; 2015.

11. James PA, Oparil S, Carter BL, Cushman WC, Dennison-Himmelfarb C, Handler J, Lackland DT, et al. 2014 evidence-based guideline for the management of high 
blood pressure in adults: report from the panel members appointed to the Eighth Joint National Committee (JNC 8). JAMA. 2014;311(5):507-520.

12. Cardiologia SBd. V Diretriz Brasileira de Dislipidemias e Prevencao da Aterosclerose. Classificacao das dislipidemias. Arq Bras Cardiol. 2013;101(4Supl.1):5.

13. Junior JER. Doenca Renal Cronica: Definicao, Epidemiologia e Classificacao. J Bras Nefrol. 2004; XXVI - no 3 - Supl. 1.

14. Obesity: preventing and managing the global epidemic. Report of a WHO consultation. World Health Organ Tech Rep Ser. 2000;894:i-xii, 1-253.

15. Federation ID. The IDF consensus worldwide definition of the metabolic syndrome. Available: http://www.idf. org/metabolic-syndrome.

16. The effect of intensive treatment of diabetes on the development and progression of long-term complications in insulin-dependent diabetes mellitus. The Diabetes Control and Complications Trial Research Group. N Engl J Med. 1993;329(14):977-986.

17. Diabetes SBd. Diretrizes da Sociedade Brasileira de Diabetes. In. Sao Paulo; 2014-2015:271-277.

18. Malerbi DA, Franco LJ. Multicenter study of the prevalence of diabetes mellitus and impaired glucose tolerance in the urban Brazilian population aged 30-69 yr. The Brazilian Cooperative Group on the Study of Diabetes Prevalence. Diabetes Care. 1992;15(11):1509-1516.

19. Borges NB, Ferraz MB, Chacra AR. The cost of type 2 diabetes in Brazil: evaluation of a diabetes care center in the city of Sao Paulo, Brazil. Diabetol Metab Syndr. 2014;6(1):122.

20. Tight blood pressure control and risk of macrovascular and microvascular complications in type 2 diabetes: UKPDS 38. UK Prospective Diabetes Study Group. BMJ. 1998;317(7160):703-713.

21. Das S, Haroled Peter PL, Bhavani ML, Naresh P, Ramana MV. Age- and Sex-related Prevalence and Drug Utilization Pattern in the Management of Type 2 Diabetes Mellitus and its Comorbidity with Cardiovascular Diseases: A Comparative Study. Indian J Pharm Sci. 2015;77(4):478484.

22. Alvim Rde O, Mourao-Junior CA, de Oliveira CM, Krieger JE, Mill JG, Pereira AC. Body mass index, waist circumference, body adiposity index, and risk for type 2 diabetes in two populations in Brazil: general and Amerindian. PLoS One. 2014;9(6):e100223.

23. Flor LS, Campos MR, Oliveira AF, Schramm JM. Diabetes burden in Brazil: fraction attributable to overweight, obesity, and excess weight. Rev Saude Publica. 2015;49:29.

24. Almeida-Pititto B DM, Moraes ACF, Ferreira SRG, Franco DR, Eliaschewitz FG. c. Dove Press Journal. 2015;8.

25. (6) Glycemic targets. Diabetes Care. 2015;38(Suppl):S33-40.

26. Garber AJ, Abrahamson MJ, Barzilay JI, Blonde L, Bloomgarden ZT, Bush MA, Dagogo-Jack S, et al. American Association of Clinical Endocrinologists' comprehensive diabetes management algorithm 2013 consensus statement - executive summary. Endocr Pract.
2013;19(3):536-557.

27. Shah BR, Hux JE, Laupacis A, Mdcm BZ, Austin PC, van Walraven C. Diabetic patients with prior specialist care have better glycaemic control than those with prior primary care. J Eval Clin Pract. 2005;11(6):568-575.

28. Andel M, Grzeszczak W, Michalek J, Medvescek M, Norkus A, Rasa I, Niewada M, et al. A multinational, multi-centre, observational, cross-sectional survey assessing diabetes secondary care in Central and Eastern Europe (DEPAC Survey). Diabet Med. 2008;25(10):1195-1203.

29. Jorgensen LG, Petersen PH, Heickendorff L, Moller HJ, Hendel J, Christensen C, Schmitz A, et al. Glycemic control in diabetes in three Danish counties. Clin Chem Lab Med. 2005;43(12):1366-1372.

30. Esposito K, Chiodini P, Ceriello A, Giugliano D. A nomogram to estimate the proportion of patients at hemoglobin A1c target $<7 \%$ with noninsulin antidiabetic drugs in type 2 diabetes: a systematic review of 137 randomized controlled trials with 39,845 patients. Acta Diabetol. 2014;51(2):305-311.

31. Alvarez Guisasola F, Mavros P, Nocea G, Alemao E, Alexander CM, Yin D. Glycaemic control among patients with type 2 diabetes mellitus in seven European countries: findings from the Real-Life Effectiveness and Care Patterns of Diabetes Management (RECAP-DM) study. Diabetes Obes Metab. 2008;10(Suppl 1):8-15.

32. Pittrow D, Stalla GK, Zeiher AM, Silber S, Marz W, Pieper L, Klotsche J, et al. [Prevalence, drug treatment and metabolic control of diabetes mellitus in primary care]. Med Klin (Munich). 2006;101(8):635-644.

33. Goudswaard AN, Stolk RP, Zuithoff P, Rutten GE. Patient characteristics do not predict poor glycaemic control in type 2 diabetes patients treated in primary care. Eur J Epidemiol. 2004;19(6):541-545.

34. Hoerger TJ, Segel JE, Gregg EW, Saaddine JB. Is glycemic control improving in U.S. adults? Diabetes Care. 2008;31(1):81-86.

35. Rui Lyra NC, Raul Dias Santos. Diabetes mellitus e doencas cardiovasculares. $1^{a}$ ed. Sao Paulo; 2014.

36. Moreira GC, Cipullo JP, Ciorlia LA, Cesarino CB, VilelaMartin JF. Prevalence of metabolic syndrome: association with risk factors and cardiovascular complications in an urban population. PLoS One. 2014;9(9):e105056.

37. Schmid A, Schneider H, Golay A, Keller U. Economic burden of obesity and its comorbidities in Switzerland. Soz Praventivmed. 2005;50(2):87-94.

38. Kovesdy CP, Sharma K, Kalantar-Zadeh K. Glycemic control in diabetic CKD patients: where do we stand? Am J Kidney Dis. 2008;52(4):766-777.

39. KDOQI Clinical Practice Guideline for Diabetes and CKD: 2012 Update. Am J Kidney Dis. 2012;60(5):850886.

40. Diabetes SBd. Diretrizes da Sociedade Brasileira de Diabetes In. Sao Paulo; 2014-2015:361-369.

41. Camargo JL, Gross JL. [Glycohemoglobin (GHb): clinical and analytical aspects]. Arq Bras Endocrinol Metabol. 2004;48(4):451-463.

42. Norkus A OR, Zalinkevicius R, Radzeviciene L, Sulcaite $\mathrm{R}$. Adequate prescribing of medication does not neces- 
sarily translate into good control of diabetes mellitus. In, Patient Prefer Adherence; 2013:643-652.

43. McIntosh B, Cameron C, Singh SR, Yu C, Dolovich L, Houlden R. Choice of therapy in patients with type 2 diabetes inadequately controlled with metformin and a sulphonylurea: a systematic review and mixed-treatment comparison meta-analysis. Open Med. 2012;6(2):e62-74.

44. Holman RR, Paul SK, Bethel MA, Matthews DR, Neil HA. 10-year follow-up of intensive glucose control in type 2 diabetes. N Engl J Med. 2008;359(15):1577-1589. 